\title{
The unbearable dispersal of being: Narrativity and personal identity in borderline personality disorder
}

\author{
Philipp Schmidt ${ }^{1,2,3}$ (D) Thomas Fuchs ${ }^{3}$
}

Accepted: 14 November 2020 / Published online: 15 December 2020

(C) The Author(s) 2021

\begin{abstract}
Borderline personality disorder (BPD) is characterized by severe disturbances in a subject's sense of identity. Persons with BPD suffer from recurrent feelings of emptiness, a lack of self-feeling, and painful incoherence, especially regarding their own desires, how they see and feel about others, their life goals, or the roles to which they commit themselves. Over the past decade or so, clinical psychologists, psychotherapists, and psychiatrists have turned to philosophical conceptions of selfhood to better understand the borderline-specific ruptures in the sense of identity, which are frequently associated with severe affective instability and turbulence in interpersonal relationships. Fuchs (2007) has suggested that these disturbances in self-experience can best be described and explained by using notions - widely discussed in philosophy and psychology-of narrativity and narrative identity. On such a narrative view, key features of BPD present significant modifications of proto-narrative structures and inhibit the development of a narrative identity, resulting in a disturbed sense of identity. Although the role of narrativity in BPD has been acknowledged by many researchers, some have voiced dissatisfaction with what they take to be limitations of a narrativistic understanding of the disorders of identity characterizing BPD, and have proposed alternative, allegedly non-narrativistic, accounts. In this paper, we critically examine an example of the latter, viz. Gold and Kyratsous' (2017) account of the person as an intrapersonal team reasoner. We defend a narrativistic understanding of BPD identity disorder against their objections. To this end, we propose a broader, and more finely-differentiated, concept of narrativity. On this account, four aspects of narrativity are distinguished, the disordering of which can affect those with BPD. As it turns out, our account implies that even Gold and Kyratsous - in order to ground their approach - must either make use of these aspects or propose an as-yet unarticulated alternative. This casts doubt upon whether their approach is non-narrativistic after all.
\end{abstract}

Keywords Borderline personality disorder (BPD) $\cdot$ Personal identity $\cdot$ Narrativity $\cdot$ Selfexperience $\cdot$ Episodics $\cdot$ Intrapersonal team reasoning 


\section{Introduction}

Topher Edwards describes his condition, having been diagnosed with borderline personality disorder (BPD), as a "life-long battle - a war raging between me and myself" (Edwards 2017, p. 159). His pain is palpable when he further reports: "[misery] follows me everywhere. Bad luck clings to me, and everyone I get close to seems to end up wanting nothing to do with me. It's obvious that the common denominator is ME." (Edwards 2017, p. 154). Moreover, his online diaries (Edwards 2015, 2016, 2017) are replete with statements reflecting a deep puzzlement about himself: "I feel, for the most part, that I am only just existing. I am part of a continuum but no more, potentially less" (Edwards 2015, p. 49), "I feel like a ghost masquerading as a human being" (p. 45), or "That's me ... an entity. Invisible to most, simply empty and abstract" (p. 14).

Feelings of emptiness or a lack of identity contributes significantly to the "mental pain" that is characteristic of persons with BPD (Fertuck et al. 2016). They express feelings of "rotting away" (Edwards 2017, p. 27), being "deadened" or "not human" (Singer 1987, p.133). The "contradiction between feeling non-existent and being alive" is "overwhelming" says Emma, a young woman with BPD (Black et al. 2014, p. 80). These testimonies are clear indications of a painful disturbance in self-experience.

Crucially, the diminished or weakened sense of identity in BPD is not an isolated phenomenon, but comes with altered, heterogeneous, and unstable forms of selfexperience, which generate "painful incoherence" (Meares et al. 2011) in emotional life; in perceiving, labelling, and regulating one's own emotions (Carpenter and Trull 2013; New et al. 2012; Nica and Links 2009; Peters and Geiger 2016); in feeling, thinking, and behaving with regard to other people (Lazarus et al. 2014; Ratcliffe and Bortolan 2021); as well as in committing to, and fulfilling, one's own projects, life goals, or professional roles.

To better understand the interrelations between the different ways of experiencing oneself and others in the various circumstances of life, clinical psychologists, psychotherapists, and psychiatrists have increasingly turned to philosophical conceptions of selfhood to gain insight into disorders of identity. One suggestion by Fuchs (2007) has been to describe the BPD-related disorder of self in terms of a rupture in narrative processes, contributing to a fragmentation of what is often referred to as narrative identity: the sense of being both the author and the protagonist in one's own life story. In the past decade, the notion that processes of narrativity and their malfunction may assist us in understanding self-experience and identity disturbances in BPD has been accepted and further developed by many researchers (for example, Adler et al. 2012; Bortolan 2018; Bortolan 2020; Lo Monte and Englebert 2018; Stanghellini and Rosfort 2013a, 2013b; Zandersen and Parnas 2019).

On the other hand, various authors have raised doubts about the explanatory role of narrativity in the kind of self-experience characteristic of BPD. One such example is the account of Gold and Kyratsous (2017). Adopting Strawson's (2008, 2017) conceptual distinction between 'Diachronics' and 'Episodics', they argue that, while some people experience their lives as proceeding in a coherent and continuous process of motivated and interrelated events (as if lived by a coherent and persistent 'diachronic' self), others experience a succession of distinct selves that only last as long as a given experiential episode. In agreement with Strawson, they emphasize that, to be an Episodic is not in 
itself pathological, and need not be experienced as such. Hence, they argue, a lack of narrative identity does not explain the pathological aspects of BPD self-experience. As an alternative, they offer what they call an agentic account, involving a pluralist or collaborative notion of person or selfhood as a complex of sub-personal agents. A person is viewed as "composed of a 'team' of transient agents" whose dynamics are organized according to "intrapersonal team reasoning" (Gold and Kyratsous 2017, p. 1024). BPD self-pathology, they propose, can be understood as a disruption of agentic processes and group identification among intrapersonal team members.

Our aim in this paper is to examine the proposal made by Gold and Kyratsous and show thereby that it does not support an objection to a narrativistic understanding of BPD, of the kind described by Fuchs (2007). Our rejoinder also applies to a more general skepticism concerning the role of narrativity in the structure of a person's selfexperience, as found, for instance, in Strawson (2008, 2010, 2020) or Lamarque (2004). We will argue that these skeptical authors share a rather narrow notion of narrativity, consisting in the view that (a) narrativity necessarily involves an act of narration, and (b) a person's life is narratively structured only if she engages in a narration of her life as a whole or orients herself within a single, stable, and coherent narrative. By contrast, we propose a concept of narrativity that is broader in scope, allowing us to distinguish different aspects of narrativity that we suggest structure a person's self-experience in different ways. We begin with a discussion of Gold and Kyratsous' account and their criticism of the narrativistic approach to BPD, which will motivate our broader concept of narrativity. We will proceed as follows:

1. We will argue that the main line of argument put forward by Gold and Kyratsous, contrary to its intention, does not undermine a narrativistic explanation of BPD identity disorder;

2. In response to their criticism, and to elucidate the explanatory potential of disturbed narrativity for BPD, we propose a broader notion of narrativity, which involves a distinction between narrative, narrative identity, proto-narrative, and proto-narrative structures;

3. Based on this concept of narrativity, we provide examples of how processes involved in the development of narrative identity are disturbed in BPD, and how this is related to its other symptoms, thereby illustrating the explanatory potential of a narrativistic understanding of BPD;

4. From the vantage point of the broader concept of narrativity that we propose, we argue that Gold and Kyratsous's alternative model of the person as an intrapersonal team of transient agents itself relies on narrative understanding in a relevant sense.

\section{Healthy non-narratives?}

We begin by discussing a central tenet of Gold and Kyratsous' critique of narrativistic understandings of BPD self-pathology: the assumption that healthy persons exist who are non-narrative, implying that an absence of narrative is not pathological in itself, and thus fails to explain the disturbance of self and identity witnessed in BPD. Inspiring Gold and Kyratsous' view is Galen Strawson: 
If I consider myself, I find that my self-biography is just a chronology, a list of dates. It's a filing cabinet (mostly empty). It doesn't in any way represent progression. It involves no narrative flow, although I can of course report certain causal sequences (but I am bad at this). It does mark a few 'moments of being', in Virginia Woolf's sense, events that I know occurred in my life and about which I feel strong emotions. (Strawson 2020, p. 141)

Strawson emphasizes that he-unlike 'Diachronics', who perceive themselves as having a persistent sense of self - instead experiences what he describes as an 'episodic' life (Strawson 2017, p. 51); a life constituted by "moments of being, snapshots, fundamentally non narrative within themselves, and not phenomenologically part of any larger containing sequence or "narrative"' (Strawson 2020, p. 141). Appealing to the notion of "deep human differences" (Strawson 2018, p. 195), Strawson rejects the idea that the self-experience of all persons centers around a narrative.

Gold and Kyratsous (2017, p. 1024) find that "if Strawson is right that the nonclinical population can be nonnarrative, that challenges the idea that lack of narrative causes the pathology in BPD”. This suggests a simple view of narrativity, according to which one either has it or not. Since healthy persons can lack narrativity in this sense, its absence does not by itself explain pathology. The implication is therefore made that a specific narrativity thesis about BPD self-pathology, for instance as offered by Fuchs (2007), fails owing to the falsity of a more general thesis that we may call "strong narrative self-constitution": that "all normal people constitute their identity as persons or selves by virtue of being narrative" (Strawson 2020, p. 124). The idea behind Gold and Kyratsous' criticism, thus, is that if a narratively structured sense of identity is not essential to human personhood and not shared by all healthy persons, then an absence of narratively structured sense of identity cannot explain any pathology, a fortiori the pathologies of the self in BPD.

Granting that the kind of episodic life Strawson describes can be found even in the non-clinical population, there are two main lines of argument to respond to the challenge that Gold and Kyratous' argument and the falsity of the strong narrative self-constitution thesis present for the weaker and more focused BPD narrativity thesis:

(1) One can raise doubts about whether the description of the experience involved in the Episodic's life can in fact be made without making use of any aspect of narrativity, i.e., whether Episodics are truly non-narrative in the strict sense;

(2) One can try to show that, contrary to Gold and Kyratsous' suggestion, explaining BPD psychopathology with reference to the disordered functioning of narrative processes does not depend on the more general thesis of strong narrative selfconstitution.

We begin with the latter, (2), by arguing that disturbed narrativity can still help us to understand BPD self-pathology, independent of whether or not the general narrative self-constitution thesis is true. While there may well be healthy non-narrative persons, disorders in narrativity may nevertheless shed light on the pathological self-experience occurring in BPD. In sections 2-4, addressing (1), we further argue that the lack of a single, coherent narrative does not amount to a complete absence of narrativity, and therefore talk of "non-narrative" persons is misleading. 
To see how narrativity is relevant to the pathological self-experience of BPD, it is helpful to compare the self-experience of healthy "non-narrative" persons with that of persons with BPD. On an initial comparison, first-person reports of persons with BPD and the Strawsonian description of the experiential life of Episodics may seem to have a lot in common. In both cases, we find a weak sense of a persistent self, paired with a feeling of puzzlement concerning past occurrences and experience. Feelings of not being at one with the self one remembers are common in both descriptions. Attention seems to be focused on the present rather than on the future or past.

However, on a further inspection, apparent similarities quickly dissolve. One dissimilarity is that there seem to be different ways of relating to the self in each case. Strawson refers to the philosopher A. J. Ayer as a witness to an episodic life who said of himself: "I wonder whether I do even have an image of myself? ... I don't think I'm all that much interested in myself. I'm much more interested in trying to solve philosophical problems, or in what's happening around me," (Rogers 1999, p. 286; Strawson 2020, p. 140). In marked contrast, persons with BPD are typically concerned about themselves and their character, and are often distressed by their perception of its absence or weakness, as reflected in another quote by Edwards (2016, p. 40): "I have spent my life searching. Searching for who I am, who and what I am supposed to be."

Lacking any other means to make sense of the painful emptiness they find within themselves, persons with BPD often develop a "false self" (Jørgensen 2006, p. 635), only to learn that such a "masquerade" (Edwards 2015, p. 49) is futile: "Every time I think I have it figured out [sc. "who I really am"], the cruel hand of life bitch-slaps me with the reality that I simply do not know." (Edwards 2016, p. 108) In contrast to an episodic life, the life of a person with BPD is characterized by a struggle to develop a better self-understanding and a stable sense of identity. Yet, when these attempts are unsuccessful, they threaten to lead into a generalized self-estrangement that is described by Luyten (1987, p. 49) who reports that her patient "Dinah ... could no longer fundamentally believe in the reliability of any identity."

Moreover, although persons with BPD often ascribe "poor memory" (Luyten 1987, p. 52) to themselves, as does the Episodic Strawson (2020, p. 120), their past nonetheless features strongly in their present experience:

I feel that both my successes and mistakes over the last 22 years have molded me into who I am today. (...) Even after years, I am still haunted by mistakes I have made, people I have lost, and things I should have done differently. (Edwards 2015, p. 3)

I can't forget the Hell I went through. (Edwards 2016, p. 4)

I'm still confused. I'm still broken, trying to pick up the pieces of a life I shattered long ago. (Edwards 2016, p. 22)

Finally, although persons with BPD are similar to Episodics in lacking a stable narrative of who they are and how they have become that way, they often strive towards such a narrative and are pained by its incoherence: "(E)mbracing it [sc. the past] gives it less power to eat away who you are," (Edwards 2015, p. 4). Lacking a central narrative to provide a scaffolding for self-feeling, they are doomed not only to emptiness but also, significantly in this context, to feelings of "painful incoherence" 
(Meares et al. 2011). Wilkinson and West (Wilkinson-Ryan and Westen 2000) found that this felt incoherence, a fear of losing one's identity, feelings of a 'false self' or of emptiness, and so on, most of all distinguished BPD from other personality disorders. Similarly, Adler et al. (2012) found that a subjectively felt lack of agency and narrative coherence significantly distinguished persons with BPD from a matched control group.

As these different examples and corresponding studies show, the selfexperience of a healthy Episodic and a person with BPD, despite some prima facie similarities, is not only qualitatively, but also structurally distinct, in how it relates to their other experiences and the role it plays in their lives. What are the implications of these differences?

Firstly, while being similar to healthy Episodics in lacking a stable narrative identity, persons with BPD suffer deeply from this lack of a self-narrative they can identify with over time and that they can live up to without self-estrangement. In this case, one can acknowledge that there may well be healthy non-narrative persons and yet argue that the selfpathology of persons with BPD is at least to a large extent explained by a diminution of narrative processes and identity. This is so because persons with BPD, despite lacking narrative coherence, are very much oriented toward narrative. The lack thereof features in their self-experience, namely as painfully wanting. Such a line of argumentation is consistent with a general human difference between Episodics and Diachronics, and does not depend on the idea that healthy selves must be narratively constituted in the strong sense. In fact, a narrative explanation is compatible with human difference in this respect: for some people, the absence of a single narrative center might do no harm, while others associate it with severe "mental pain" (Fertuck et al. 2016), and find themselves lost in their lives, giving rise to or exacerbating other peculiarities such as affective instability and interpersonal turmoil. The absence of a coherent narrative identity, on this view, is not pathological as such, but can nonetheless be a factor in how and why some people perceive their life as an unbearable dispersal of being.

Although we deem this kind of response to be broadly correct, we favor a slightly different answer and, in particular, a more finely differentiated conception of narrativity. Instead of explaining BPD self-pathology simply in terms of a lack of narrative, we propose to understand it as an alteration of aspects of narrativity that involves a fragmentation of narrative self. This includes a lack of a stable narrative identity, but not a lack of an orientation towards narrative scaffolding. On our view, it is wrong to believe that narrativity is simply, let alone completely, absent in BPD. Rather, in line with Fuchs (2007), we suggest that persons with BPD display a disturbance in narrative processes that comes with an altered and painful self-experience affecting all experiential aspects that constitute a person's life (including the sense of identity). It is in this sense that examining how narrativity features in the self-experience of persons with BPD proves helpful in the explanation of BPD psychopathology — both with regard to identity disturbances and more generally. Before we can provide examples of this kind of explanation, in the next section we offer a more refined and broadened concept of narrativity.

\section{Explicitness and narrative: A broad concept of narrativity}

Critics of narrativism about selfhood often base their argument on a narrow understanding of narrative, exemplified in the following statement by Lamarque: "Narratives 
are stories that only exist when they are told. Without narration there is no narrative," (Lamarque 2004, p. 404). By contrast, we would like to suggest a concept of narrativity that distinguishes between different aspects of experienced narrativity, depending on the level of explicitness and the kind of reflective attitude involved. At least four aspects of narrativity can be discerned (for a similar though not congruent fourfold distinction, see Rudd 2012, p. 181):

\subsection{Proto-narrative structures}

Proto-narrative structures denote the intentional and motivational connections - what Jaspers (1997, p. 314) termed "meaningful psychic connections"-which structure and link our current, pre-reflective experiences, and provide the basis for possible narratives. Imagine, for instance, you are standing at your ex-partner's doormat after you have been living on another continent for five years as a consequence of a big fight that had terminated your relationship. You take a deep breath and then hit the doorbell. The feeling you have when you hit the doorbell tells - albeit subtly and implicitly - the story. Although the feeling is not yet properly a narrative, it is already narratively structured, or an "enacted narrative" (MacIntyre 1981, pp. 211 f.). For if one were to reflect on the meaning of the feeling that arises in such a situation, then one would have to engage in a form of narration.

Such a narration is not a creatio ex nihilo, but is based on the structure of one's experience as it is pre-reflectively lived through; how one finds oneself in a given situation with all the connotations and recollections associated with it. It is meant to make explicit and understandable the motivational connections which permeate that pre-reflective experience. All experiential aspects that associatively structure the unfolding of experience, therefore, are proto-narrative structures insofar as they are factors of possible narration: affectivity, bodily feeling, memory, habits or conceptual knowledge. For instance, the complex emotional feeling when hitting the doorbell in the above-mentioned example is also shaped by one's bodily feeling owing to one's immediate physiological state. If someone has a tendency towards high arousal, they would likely feel nervous and uncomfortable. This may motivate a narrative like ' 5 years were not enough to recover, it still hurts'. On the other hand, very low arousal might motivate a narrative like 'after 5 years, all that is left are memories, I don't feel anything, it's over'. ${ }^{1}$

\subsection{Proto-narratives}

Proto-narratives, we suggest, are sequentially relived or simulated experiences which unfold in our imagination or memory at a level below explicit reflection, possibly in association with mental imagery or auditory recollections. They combine remembered or imagined experiences in a meaningful way, connecting them on the basis of one's feelings, beliefs, desires, or wishes. They need not involve verbal inner speech since

\footnotetext{
${ }^{1}$ Ascribing narrativity to pre-reflective experience does not necessarily amount to the view that all prereflective experience is narrative, let alone necessarily narrative. Therefore, we suggest our position is compatible with Zahavi's notion of the minimal self, which he takes to be pre-narrative (Zahavi 2007, 2010; cf. Rudd 2012, pp. 193-200). With regard to our argument in this paper, we can and will remain agnostic about these more foundational issues.
} 
they are already present at the pre-verbal level. Consider, for instance, lying in your bed and thinking about the events of the day that has just passed. You remember that you played soccer, how you lost the game, and how angry that had made you. A slight feeling of remorse arises as you recollect how you had screamed at your friend for being a terrible goalkeeper. But then your tension releases as your memory completes the quasi-reflective episode with a recollection of the re-fraternization at the dinner. Although you have not yet told a story to anyone nor explicitly formulated one for yourself, you have relived a succession of experiences through a narrative structure, amounting to a proto-narrative.

\subsection{Narratives}

Narratives are the concrete and explicitly formulated stories we tell, either in inner speech or to others, about our life and its individuated episodes, from a first-personal perspective. We form them by reflecting upon a given experience and its protonarrative structure, or by explicitly articulating remembered proto-narratives. Narratives are therefore explicitly verbalized products of reflection.

\subsection{Narrative identity}

Narrative identity refers, on the one hand, to the experience of being both the (co-)author and the main protagonist of one's own life story, and on the other hand, to the characteristics and behaviors that result from individual episodes and longer phases of the life story of a typical individual. This may be composed of proto-narrative structures, proto-narratives, or narratives. There is a general tendency towards coherence of narrative identity, which may well include contradictory aspects and episodes, as long as the person has the impression of being able to integrate them into a view of him- or herself. In fact, narratives provide a way to integrate contradictory features of oneself. For instance, 'I am usually a very open-minded person, but my experience and behavior in the situation $x$ must be understood against the background of my experiences in situation $y$ that occurred last year'.

Our fourfold distinction is primarily concerned with experiential aspects of narrativity and how they feature in self-experience. As such, it is a phenomenological rather than an ontological approach to narrative identity. That doesn't mean a phenomenological proposal like ours has no ontological implications. Yet, our concern here is not with the ontological issues of personal identity. That said, we would like to emphasize that we do not consider narrative identity to be merely an experiential fiction that grounds a similarly fictitious idea of self, as, for instance, Dennett (1991, Ch. 13) has famously proposed. Neither would we agree with a position like Velleman's (2006), according to which it is only by virtue of narration, allegedly occurring on a sub-personal level, that the self is brought into being. ${ }^{2}$

Rather, our claim is that the sense of identity as a person over time is narratively structured. The form of personal identity is narrative, in the sense that whatever our identity really consists in, it is such that it can be narrated. Following Rudd, we suggest this gives rise to what could be called a Kantian regulative idea of an "ideally truthful

\footnotetext{
${ }^{2}$ On the diachronic continuity of the pre-reflective and pre-narrative embodied self, see Fuchs 2017.
} 
narrative, one that really does (or would) correspond to the (proto-)narrative structure of my life, whether or not this ideal narrative is ever actually told" (Rudd 2012, p. 181). It is against the background of such an idea that any individual proto-narrative or narrative can turn out to be distortive or one-sided. This means only a better and more accurate narrative can possibly falsify a given narrative (cf. Rudd 2012, p. 181).

Note that, by invoking an ideally truthful narrative, we are not referring to an ethically ideal narrative, nor an alleged norm to try to live by one's ideally true narrative. In this sense, our account is purely descriptive. The only claim about normativity that we are making is that any narrative that purports to falsify another does so by at least implicitly affirming the idea of a true narrative: a narrative corresponding to the actual events of one's life. To avoid another possible misunderstanding, neither are we subscribing to the idea of a "true self" that somehow underlies all our practices and narratives about ourselves, as a form of predestination, as it were, and that we should realize in our lives. All we want to say is that, in order to understand who a person is in the details of her individuality, it will be necessary to make use of narratives, and these narratives at least implicitly refer to an ideally true narrative. For instance, take all the biographies and stories about Napoleon. Most of them will likely say something truthful about Napoleon, without telling the whole story of his life. Each narrative nevertheless purports to present an aspect of Napoleon's life, thereby affirming the idea of a complete story of his life against which the truth of the partial narratives can be measured.

Finally, in distinguishing these four aspects of experiential narrativity, we do not want to claim to have exhaustively described narrativity, let alone resolved the ontological issues regarding the relationship between narrativity and selfhood (and personhood). We consider our proposal to be pragmatic in the sense that it can be accepted by proponents with different stances on the ontological issue of identity and the role of narrativity therein. In fact, we would go so far as to claim that any account of identity and narrativity must be compatible with the fourfold phenomenologically motivated distinction of the experiential aspects of narrativity given here. However, in this context, what matters is that these four aspects need to be taken into account to understand the kind of disturbance in narrative processes to be found in BPD selfexperience.

\section{The unbearable dispersal of being: Disturbed Narrativity in borderline personality disorder}

All four levels of narrativity can be, and often are, disturbed in BPD. Given their intrinsic interrelatedness, disorders that concern one aspect are likely to engender and correlate with disturbances on other levels. Crucially, narrativity is embedded within other experiential dimensions, such as affectivity, intersubjectivity, or embodiment (Gallagher 2013; Sass 2014; Gallagher and Daly 2018; Fuchs and Pallagrosi 2018). As a consequence, disorders of affectivity, for instance, may result in a disturbance of proto-narrative structures, which gives rise to a distortion of proto-narratives and then narratives in a way that adversely affect how a person relates to other people. The different aspects of narrativity and their disturbance, therefore, might help to elucidate how disorders of certain experiential dimensions may affect each other, and explain the 
connection between the different pathological features of BPD. We suggest this applies to the three core instabilities to be found in BPD: instability in affect, interpersonal relationships, and identity (American Psychiatric Association 2013, p. 663). A few examples may suffice to illustrate how the four-level concept of narrativity presents an explanatory framework that allows a better understanding of how these instabilities are connected.

\subsection{Disturbances of proto-narrative structures}

One of the central features of borderline affective instability concerns processes of emotion dysregulation (Nica and Links 2009; New et al. 2012; Carpenter and Trull 2013), which shape proto-narrative structures. For instance, impulsivity, which is commonly felt as irascibility, may amount to a tendency to experience situations in a way whereby one feels exposed to one's environment and other people. Combined with alexithymia (a deficiency in identifying emotions), as well as a lack of skills in regulating emotions, feelings of being exposed and out of control may arise. These feelings shape the meaning attributed to a given situation, and hence the character of the proto-narrative structure corresponding to it. Often the interpretation of the situation in BPD involves a neglect of one's own contribution to the situation, as the locus of control is ascribed to other people or the environment. Other people may appear threatening or as a safe haven on which one can depend. All of these aspects significantly determine how one responds to a situation, constraining the role that the agent may play therein. This effect of disturbed proto-narrative structures is particularly acute in BPD, given that a more stable and balanced narrative identity is not available to provide scaffolding. Instead, momentary emotional processes and interpersonal problems heavily determine what kind of narratives persons enact, rather than being shaped by a more comprehensive life-narrative.

\subsection{Disturbances of proto-narratives}

Crucially, the proto-narrative structures that are typical of BPD also inform the ways in which people engage in proto-narrating, especially in terms of frequency and intensity. The lack of control over one's situation, recurring interpersonal problems, and strong, concomitant negative emotions evoke a tendency to relive painful situations through proto-narratives, combining selected memories and feelings in which the unfolding of a situation is recollected. Importantly, proto-narratives are often precisely the way in which a strong mood or affect unfolds. The experiential reliving of certain experiences or aspects thereof can be the direct expression of dysregulative practices: for instance, when someone recalls over and over the words said by another person and the negative feelings attached to them. In this manner, anger and its intentionality often consist, at least partially, in an on-going recollection of corresponding past experiences.

These recollections unfold as proto-narratives, which are frequently the firstpersonal correlate of the often-observed incapability of persons with BPD to let something go. The almost obsessive engagement in proto-narrating - what could be called a borderline-specific narrative hyperreflexivity-in fact generates a tendency towards escalation in situations of conflict. This tendency is amplified by the oftenbiased manner in which proto-narratives are formed and structured in BPD. Memories 
are guided by feelings of being exposed and undermined. They correspond to the distressing aspects of the emotional experience and sometimes even involve components of fantasy or confabulation. In this manner, persons with BPD often feature in these proto-narratives as victims (Stanghellini and Mancini 2018). By contrast with healthy individuals, proto-narratives do not help persons with BPD to gain a better understanding of a situation; much rather, they often distort their perspective. Together with the interrelated alexithymia and lack of other regulatory skills, dysfunctional and distorted proto-narratives emerge as the experiential background for impulsive behavior that often aggravates pre-existing interpersonal conflicts (Wright et al. 2013).

\subsection{Disturbances of narratives}

It is not only through impulsive or problematic behavior that interpersonal conflicts are aggravated for those with BPD: the dysfunctions in proto-narrativity already discussed further lead to problems thanks to their role in the formation of narratives. Even when a person with BPD tries to communicate and verbally express their proto-narratives, thereby forming narratives, this often has the consequence of worsening a relationship through engendering conflict or detachment, rather than facilitating a rapprochement. This is so because of the highly distorted nature of their proto-narratives and expressed narratives, in which the other will often be the target of accusations.

In healthy individuals and relationships, the mutual communication of narratives may result in a shared narrative that reconnects people and helps them to deal with the situation collaboratively. By contrast, persons with BPD-with their distorted narratives - often find themselves rejected and isolated. Narratives lacking validation easily dissolve, however. Hence, despite the intensity of the initial reaction to a situation and its felt reality, patients are left with fragmented memories and unstable and incoherent (proto-)narrative structures involving the putative misbehavior of others, feelings of having been wronged, or regret about one's own actions which, owing to the distorting processes involved in their formation, later feel incomprehensible and have a self-alienating effect. The recurring loss of relationships also undermines the development of a more comprehensive narrative that is shared with others and socially distributed (Fuchs 2007). In order to compensate for the absence or weakness of a coherent central narrative about themselves, persons with BPD are more prone to develop ad-hoc narratives that result from an affective over-identification with the emotional experience in a given situation (Fuchs 2007; Schmidt 2020).

\subsection{Disturbances of narrative identity}

The disturbances of the prior levels may all affect narrative identity. Affective and interpersonal instability through distortions of proto-narrative structures constrains the kinds of enacted narrative that can arise and what roles and concomitant forms of identity are possible. Typically, BPD proto-narratives motivate a sense of narrative identity based on the paradigm of a traumatic situation in which one features as a victim that is exposed to others and by whom one is wronged and let down. Narratives communicated with others are often not shared and recognized by them. A lack of such recognition, as well as shifting relationships, moreover, 
harms the development and maintenance of a stable narrative identity that covers longer periods of life.

Most importantly, the absence of a stable narrative identity may not only cause the mental pain of emptiness and incoherence described previously, it may also exacerbate the distortions to the structure of a person's affective and interpersonal life stemming from the dysfunction in the prior levels of narrativity, and so help explain the peculiarities of the borderline condition with regard to these dimensions. For instance, the absence of a sense of who one is and how one has reacted to certain situations in the past may severely undermine the necessary - explicit or implicit - self-knowledge that is required to assess new situations in their meaning for oneself and to recognize how a situation integrates into one's longer perspective. This includes also an awareness of what usually allows the control of one's emotions, and what, based on prior experiences, one can expect from others. The lack of narrative identity, thus, may contribute to maintaining BPD alexithymia and emotion dysregulation. Moreover, a more or less stable narrative identity is also a stabilizing factor in interpersonal relationships: shared memories of situations and a certain degree of agreement about the roles each person involved has played in them are a basis for mutual trust, understanding and connection. By contrast, deep - let alone constantly shifting-disagreement about how the past unfolded and how each had contributed to the situations in question already is a significant disconnection from others, even prior to dispute and conflict about specific situations.

Even though the preceding analysis is hardly sufficient to provide a full understanding of the complex condition of BPD, it shows how disturbances of narrativity may be involved in the development and maintenance of instabilities in affect, interpersonal relationships, and identity (cf. Schmidt 2018; Schmidt 2021; Stanghellini and Rosfort 2010). The examples given also suggest that BPD could be described as a disorder of integration that is manifest as a fragmented identity, leading to uncontrollable affect, a detachment from others, and a lack of stable self-understanding. This is consistent both with Kernberg's famous notion of splitting (Kernberg 1975; Kernberg et al. 1989) and Linehan's most influential characterization of BPD as a dialectical disorder (Linehan 1993). We suggest that the structural ground underlying this disorder may be seen in a disturbance of narrativity and the consequent problems in integrating its various components.

\section{Narrativity and the team of intrapersonal transient agents}

We now turn to the alternative account of BPD identity disturbance proposed by Gold and Kyratsous (2017). Although they admit that the concept of narrativity may be helpful in understanding BPD psychopathology and that many researchers have acknowledged this, they suggest an alternative way to understand the fragmentation of identity in BPD that might turn out to be better-suited than a narrativistic understanding. The question we examine here, however, is whether their proposed alternative is indeed free of any implicit reference to narrativity. On a closer look, bearing in mind the broader conception of narrativity proposed here, there are grounds to be skeptical that this is really the case. 
The basic idea of Gold and Kyratsous' approach is that "[ $\mathrm{t}]$ he person over time is composed of a 'team' of transient agents" (Gold and Kyratsous 2017, p. 1024), and that the unification of these transient agents into a team is provided through identification of the current person, i.e., the synchronic self that is present now, with the team. Consider, for instance, a person constituted by two agents at different points in time: an agent who wants to go to a dinner party today and an agent who will participate in a sports competition next week. Both agents are very distinctive, not only in that they represent (or rather are) the person at different points in time, but particularly in the sense that they have contrary interests. The former is primarily focused on needs for social affiliation and the enjoyment of an evening that will include drinking wine with her friends, while the latter is primarily interested in achieving the best possible result in a sports competition, which will require maximum preparation, including healthy nutrition and getting enough sleep. How can the agent with a craving for social contact act in a responsible way that is compatible with the goals of the ambitious agent? Gold and Kyratsous (2017, p. 1024) suggest that after the identification with the team, transient agents can engage in a sort of "intrapersonal team reasoning, a model of reasoning that allows them to ask, 'What do I, as a person (team) over time, want and what actions should the present self take to achieve it?"”.

Let us emphasize that we are sympathetic to the view that a person may comprise character traits or goals that are contrary or can lead to intrapersonal conflicts, such as the combination of being extroverted and socially oriented, while also being very ambitious, goal-oriented or even dogged. Also, we admit that the idea of intrapersonal team reasoning is thought-provoking, interesting, and, most importantly, fits well with experiences of ambivalence and indecisiveness. (A different question is whether the final decision-making requires a superordinate 'chair' of the team.) When important decisions determining the personal future are at stake, people often feel torn and engage in reflection on the different possible outcomes that they envisage by imagining and feeling through anticipated situations.

To remain with the example of the person with a sports competition next week, one can imagine what it would feel like not to go to the party and to stay at home. In imagination, scenes may emerge of the party at which people talk about oneself and interpret one's absence as a statement of priority: ' $\mathrm{X}$ is more concerned about her performance than about her friends.' Fantasies may occur of how people deepen their bonds during the party, leaving oneself behind as someone who was not involved in the great dinner party. Fears of social exclusion might arise and create discomfort. On the other hand, mental images of the competition turning out badly due to tiredness and slowness as aftereffects of the dinner party may also figure as counterweights to inclinations to go to the party. Imagined anticipations of disappointment in oneself and self-accusations of lacking discipline may trigger anticipatory pangs of conscience. Such deliberations in which a situation or decision is considered from the different perspectives of one's personality may fit well with the notion of intrapersonal team reasoning, a form of self-negotiation that involves the evaluation of different views corresponding to distinctive 'parts' of oneself.

However, although the model of intrapersonal team reasoning may harmonize with some of our intuitions about our self-experience, a few important questions are left open, at least in the way Gold and Kyratsous have presented the model so far. First, they emphasize that for intrapersonal team reasoning to be possible, it is required that 
the different agents are unified through identification with the team. We agree that for any inner deliberations that weigh up different perspectives of oneself against each other, it is necessary that the perspectives are already apprehended as belonging to an individual person, and that a unification is required. This may also include the formation and examination of novel aspects of oneself, rather than only involving stable components of an already settled personality. One can imagine the kinds of reaction one would have to certain novel circumstances and try to anticipate what these would feel like, what the consequences would be, and if one is able to identify with such an attitude or behavior. Yet, Gold and Kyratsous do not explain just how the identification of an agent with the intrapersonal team ought to be performed nor what kind of phenomenological structures are involved in such identificatory processes.

Owing to this, it is no surprise that the question of the extent to which aspects of narrativity are involved in the unification of a person, i.e., the identification of the agents with the team, remains unanswered and indeterminate. This immediately provokes a further question: does the model of an intrapersonal team of transient agents really present an alternative to a narrativistic understanding of identity disturbance in $\mathrm{BPD}$ ? What is the role of narrativity in the phenomenology of the intrapersonal team of transient agents?

Evidently, or so we suggest, narrative understanding is fully compatible with the view that one is constituted as a person by a number of different sub-personal agents. In fact, literary fiction devotes much space to the development of a character by narrating what kind of distinct personal features she has. In fact, most good novels or films manifest the art of showing how very distinctive features may be found in a single person, and narrating the ensuing conflicts as well as the solutions that may resolve them. It is precisely the tension of contrary features and the way they are narrated that makes novels and films interesting. Furthermore, it is easy to imagine how intrapersonal team reasoning works on the basis of (proto-) narrative, be it experienced as inner speech or only as pre-verbal associative structures involving mental imagery, emotion, and so on. The anticipation of self-accusation in the above-mentioned case where an ambitious agent will lose the sports competition due to unpreparedness can easily be imagined to take the form of a proto-narrative in which the person experiences herself as having failed because she went to the dinner party, which can be experienced and narrated as such.

To be specific, Gold and Kyratsous do not deny that narrative understanding is compatible with their model. What they deny is that it is necessary. Hence, the more important question is whether their model of how intrapersonal team reasoning processes are disturbed in BPD is independent of narrativity, as they seem to maintain.

Now, the first aspect of narrativity we want to consider is narrative identity. Gold and Kyratsous suggest an understanding of the unification of transient agents through identification with the team in non-narrative terms. However, even if one were to grant the possibility that the unification could occur in some other way, yet to be articulated, it is difficult to conceive of any such unification without it constituting what we have termed a narrative identity. If the socially oriented agent identifies with the team to which the future ambitious agent in the sports competition also belongs, and thereby acts in a way so as to grant the best result in the competition for the ambitious agent, how can this not stem from a meaningful connection between the social and the 
ambitious agent that could be narrated, thus revealing the narrative identity of the one person who is both social and ambitious?

Gold and Kyratsous might respond that this kind of narrative may well be possible but it is not necessary to spell it out in any way. We agree when it comes to verbal expression - inner or to others. But it seems hard to imagine that the ambitious agent will not interpret her good preparedness as a result of the responsible actions of the social agent who went to bed early despite the dinner party: the narrative connections provide coherence and the rationale for the overall process.

Drawing on Strawson's notion of Episodics, Gold and Kyratsous could claim that the ambitious agent may understand that it is owing to the responsible actions of the social agent that she is, for instance, well-prepared, identifies with her via the team, but nonetheless need not feel identical with the social agent in a pronounced way. To say we belong to the same team is not equivalent to saying that the members of the team are identical with one another. We believe that there is something true to that depiction. Feelings about past experiences and the involved self may include feelings of alienation; past actions, experiences, feelings, or desires may feel strange, hard to grasp, and even absurd from the current perspective.

However, we suggest this speaks in favor of a narrativistic understanding of identity. For, even though the ambitious agent may not feel directly identical with the social agent, we propose that she nevertheless shares an experienced narrative identity with the latter. In fact, it is this narrative identity, we argue, that allows for the consideration of oneself as identical with a past or future self without necessarily feeling identical with them in the strong phenomenological sense implied in Strawson's Diachronics. If the person's life were a mere sequence of episodes without any self-identification connecting them, then the ambitious agent would not even be able to see a meaningful connection between a current episode and the former actions of the social agent. She would be identified only with her own episode. Owing to this, the intrapersonal team would dissolve.

Thus, narrative identity, rather than necessarily producing a strong phenomenological feeling of identity between one's current and past self, in fact allows for the acknowledgement and toleration of intrapersonal feelings of otherness and contrary inclinations, in such a way that they do not obstruct a general tendency towards connection and coherence of the individual. Put differently, the integrative effect of (proto-)narrative and narrative identity does not so much consist in reducing the otherness that lingers at the basis of a person, but in deescalating the irritation and dissonance that arises from that otherness. That the ambitious agent might not feel identical in a strong sense with the social agent, on this view, would not undermine the narrative identity between social and ambitious agent. Rather, narrative identity explains how the social and ambitious agents - involving quite distinctive features - can belong to the same 'team' without undermining the unity of the person. By identifying with the team, the social and ambitious agents belong to a narrative identity, an identity based on motivational and psychological connections that can be coherently narrated, even if they include deviating or contrary aspects of oneself.

This becomes yet more evident in the context of the identity disturbance in BPD. On the intrapersonal team model, different agents may identify with one another via the team without feeling identical to each other and without reference to narrative. We have already argued that it remains unclear how such unification 
could be established. What is moreover unclear is how exactly the model explains identity disturbance itself, i.e., the pathology of BPD. What is it that makes intrapersonal otherness so painful in these cases? Gold and Kyratsous argue that intrapersonal heterogeneity is not in itself pathological. While we agree, we would argue that it is precisely narrative identity that usually helps to reduce the friction between contrary aspects of one's own personality or phases of life. Narrative identity has an integrative function, which can lead to a stronger sense of continuity or lessen the irritation that stems from feelings of discontinuity. Without a stable narrative identity and with strong shifts and variance in character traits, persons with BPD suffer from the irritation of intrapersonal otherness. By contrast, without invoking narrative identity, it is far from obvious how the intrapersonal team model can provide an explanation as to why a heterogeneous intrapersonal team is associated in the case of BPD with painful incoherence, while in healthy persons it is not. To put it pointedly: on Gold and Kyratsous' account, there is no reason why BPD patients should suffer from their episodic or fragmented lives.

Moreover, having distinguished the four different aspects of narrativity, it seems even less likely that one can account for BPD psychopathology without involving narrativity in some way. Even if one were to acknowledge the intrapersonal team as some kind of alternative to narrative identity, it is hard to see how intrapersonal team reasoning would be possible without something that binds together the different agents, their inclinations, wishes, and goals. Gold and Kyratsous suggest that the agents correspond to different points of time or episodes. How would these agents become involved in the intrapersonal team reasoning process if not by memory involving narratives and consequent connections between the various agents? To involve a certain agent in deliberations, she must have some characteristic profile derived from a recollection of the situations in which the agent was actual. The temporal unfolding of an episode belonging to a given agent and the experiential dynamics involved must be remembered and brought to mind in some form, and it is hard to see how this could not have the form of a (proto-)narrative, or at least of something that has an intrinsically narratable structure.

To sum up, the intrapersonal team model suggested by Gold and Kyratsous presents an interesting account of intrapersonal plurality and otherness. However, not only does it leave open how exactly the unification of agents into a team occurs, it is also implausible that this can be explained without relying on any aspects of narrativity. In particular, understanding the identity disturbance in BPD seems to require some reference to a notion of narrative identity, even if one endorses the view of a person as an intrapersonal team of transient agents. Therefore, we suggest that the latter does not present an alternative to a narrativistic understanding of BPD, but is rather complementary to it.

\section{Conclusion}

Our aim in this paper was to defend the view that describing BPD as a disturbance of narrativity improves our understanding and explanation of borderline psychopathology, particularly the disorder of identity involved. More specifically, we argued in favor of 
the following claims about the meaning, aspects, scope, and relevance of narrativity, proposing a more differentiated notion of narrativity than is often considered in the debate:

(1) narrativity is not to be grasped in binary terms (one either lives by a single narrative or one does not), but comprises a complex interplay of proto-narrative structures, proto-narrative, narratives, and narrative identity;

(2) human persons vary in how much they are oriented within a single and coherent narrative and narrative identity, and separately, in how they feel affected by a lack of a coherent narrative and narrative identity;

(3) even those people who are barely if at all oriented within a single and coherent narrative nonetheless are not entirely non-narrative, because their experiential life is still shaped by proto-narrative structures, proto-narratives, and narratives that organize their memories and lived experience;

(4) there is nothing pathological per se about not being oriented within a single and coherent narrative; however, this does not mean that a lack of narrative identity cannot help to explain BPD identity disturbances and the concomitant instabilities in affect and interpersonal relationships;

(5) BPD may involve disturbances of all four aspects of narrativity;

(6) the intrapersonal team model proposed by Gold and Kyratsous (2017) presents a complement, rather than an alternative, to a narrativistic understanding of BPD identity disorder, given that any such model will have to comprehend at least some aspects of narrativity.

To conclude, the distinction between narrative and non-narrative, we suggest, is too crude. Different aspects of narrativity need to be distinguished. While not all persons are oriented within a coherent single life narrative, nor engage in the development of a single narrative identity, other aspects of narrativity such as proto-narrative structures, proto-narratives, and narratives are pervasive in their experiential life, and defects in these can help explain pathology.

Authors' contributions not applicable.

Funding Open Access funding enabled and organized by Projekt DEAL.

Data availability not applicable.

\section{Compliance with ethical standards}

Conflicts of interest. not applicable.

Code availability not applicable.

Open Access This article is licensed under a Creative Commons Attribution 4.0 International License, which permits use, sharing, adaptation, distribution and reproduction in any medium or format, as long as you give appropriate credit to the original author(s) and the source, provide a link to the Creative Commons licence, and indicate if changes were made. The images or other third party material in this article are included in the article's Creative Commons licence, unless indicated otherwise in a credit line to the material. If material is not 
included in the article's Creative Commons licence and your intended use is not permitted by statutory regulation or exceeds the permitted use, you will need to obtain permission directly from the copyright holder. To view a copy of this licence, visit http://creativecommons.org/licenses/by/4.0/.

\section{References}

Adler, J. M., Chin, E. D., Kolisetty, A. P., \& Oltmanns, T. F. (2012). The distinguishing characteristics of narrative identity in adults with features of borderline personality disorder: An empirical investigation. Journal of Personality Disorders, 26, 498-512.

American Psychiatric Association. (2013). Diagnostic and statistical manual of mental disorders (5th ed.). Arlington: Author.

Black, G., Murray, J., \& Thornicroft, G. (2014). Understanding the phenomenology of borderline personality disorder from the patient's perspective. Journal of Mental Health, 23(2), 78-82.

Bortolan, A. (2020). Narratively shaped emotions: The case of borderline personality disorder. Journal of Medicine and Philosophy, 45(2), 212-230.

Bortolan, A. (2018). Phenomenological psychopathology and autobiography. In G. Stanghellini, M. Broome, A. Fernandez, P. Fusar-Poli, A. Raballo, \& R. Rosfort (Eds.), Oxford handbook of phenomenological psychopathology (pp. 1052-1064). Oxford: Oxford University Press.

Carpenter, R. W., \& Trull, T. T. (2013). Components of emotion dysregulation in borderline personality disorder: A review. Current Psychiatry Reports, 15(1), 335.

Dennett, D. (1991). Consciousness explained. Harmondsworth: Penguin.

Edwards, T. (2015). The BPD journals I: A year in the life. San Francisco, CA: Blurb.

Edwards, T. (2016). The BPD journals II: Remission and relapse. San Francisco, CA: Blurb.

Edwards, T. (2017). The BPD journals III: Stable instability. San Francisco, CA: Blurb.

Fertuck, E. A., Karan, E., \& Stanley, B. (2016). The specificity of mental pain in borderline personality disorder compared to depressive disorders and healthy controls. Borderline Personality Disorder and Emotion Dysregulation, 3. https://doi.org/10.1186/s40479-016-0036-2.

Fuchs, T. (2007). Fragmented selves: Temporality and identity in borderline personality disorder. Psychopathology, 40, 379-387.

Fuchs, T. (2017). Self across time: The diachronic unity of bodily existence. Phenomenology and the Cognitive Sciences, 16, 291-315.

Fuchs, T., \& Pallagrosi, M. (2018). Phenomenology of temporality and dimensional psychopathology. In M. Biondi, M. Pasquini, \& A. Picardi (Eds.), Dimensional psychopathology (pp. 287-300). Cham: Springer.

Gallagher, S. (2013). A pattern theory of self. Frontiers in Human Neuroscience, 7. https://doi.org/10.3389/ fnhum.2013.00443.

Gallagher, S., \& Daly, D. (2018). Dynamical relations in self-pattern. Frontiers in Psychology, 9. https://doi. org/10.3389/fpsyg.2018.00664.

Gold, N., \& Kyratsous, M. (2017). Self and identity in borderline personality disorder: Agency and mental time travel. Journal of Evaluation in Clinical Practice, 23, 1020-1028.

Jaspers, K. (1997). General psychopathology, trans. J. Hoenig \& M.W. Hamilton. Baltimore: Johns Hopkins University Press.

Jørgensen, C. R. (2006). Disturbed sense of identity in borderline personality disorder. Journal of Personality Disorders, 20(6), 618-644.

Kernberg, O. F. (1975). Borderline conditions and pathological narcissism. New York: Aronson.

Kernberg, O. F., Selzer, M. A., Koenigsberg, H. W., Carr, A. C., \& Appelbaum, A. (1989). Psychodynamic psychotherapy of borderline patients. New York: Basic Books.

Lamarque, P. (2004). On not expecting too much from narrative. Mind and Language, 9(4), 393-408.

Lazarus, S. A., Cheavens, J. S., Festa, F., \& Rosenthal, M. Z. (2014). Interpersonal functioning in borderline personality disorder: A systematic review of behavioral and laboratory-based assessments. Clinical Psychology Review, 34(3), 193-205.

Linehan, M. M. (1993). Cognitive-Treatment of Borderline Personality Disorder. New York a. London: The Guilford Press.

Lo Monte, F., \& Englebert, J. (2018). Borderline personality disorder and lived time. L'Évolution Psychiatrique, 84(4), e37-e45.

MacIntyre, A. (1981). After virtue. Notre Dame: University of Notre Dame Press. 
Meares, R., Gerull, F., Stevenson, J., \& Korner, A. (2011). Is self-disturbance the core of borderline personality disorder? An outcome study of borderline personality factors. Australian and New Zealand Journal of Psychiatry, 45, 214-222.

New, A. S., aan het Rot, M., Ripoll, L. H., Perez-Rodriguez, M. M., Lazarus, S., Zipursky, E., Siever, L. J., et al. (2012). Empathy and alexithymia in borderline personality disorder: Clinical and laboratory measures. Journal of Personality Disorder, 26(5), 660-675.

Nica, E. I., \& Links, P. S. (2009). Affective instability in borderline personality disorder: Experience sampling findings. Current Psychiatry Reports, 11, 74-81.

Peters, J. R., \& Geiger, P. J. (2016). Borderline personality disorder and self-conscious affect: Too much shame but not enough guilt? Personality Disorders Theory Research and Treatment, 7(3), 303-308.

Ratcliffe, M. \& Bortolan, A. (2021). Emotion regulation in a disordered world: Understanding borderline personality disorder. In G. Stanghellini \& C. Tewes (Eds.): Time and Body: Phenomenological and Psychopathological Approaches (pp. 177-200). Cambridge: Cambridge University Press.

Rogers, B. (1999). A. J. Ayer. London: Chatto \& Windus.

Rudd, A. (2012). Self, value, and narrative. A Kierkegaardian Approach. Oxford: Oxford University Press.

Sass, L. A. (2014). Explanation and description in phenomenological psychopathology. Journal of Psychopathology, 20, 366-376.

Schmidt, P. (2018). The relevance of explanatory first-person approaches (EFPA) for understanding psychopathological phenomena: The role of phenomenology. Frontiers in Psychology, 9. https://doi.org/10. 3389/fpsyg.2018.00694.

Schmidt, P. (2020): Störungen des Selbst in der Borderline-Persönlichkeit: Der Zusammenhang von Affekt und Identitätserleben. In T. Fuchs \& T. Breyer (Eds.), Selbst und Selbststörungen (pp. 165-193). Freiburg, Germany: Karl Alber.

Schmidt, P. (2021): Nobody? Disturbed self-experience in borderline personality disorder and four kinds of instability. In G. Stanghellini \& C. Tewes (Eds.), Time and Body: Phenomenological and Psychopathological Approaches (pp. 206-229). Cambridge: Cambridge University Press.

Singer, M. (1987). A phenomenology of the self: Appersonalization, a subcategory of borderline pathology. Psychoanalytic Inquiry. A Topical Journal for Mental Health Professionals, 7(1), 121-137.

Stanghellini, G. \& Mancini, M. (2018). The life-worlds of persons with borderline personality disorder. In G. Stanghellini, M. Broome, A. V. Fernandez, P. Fusar-Poli, A. Raballo, R. Rosfort (Eds.), The Oxford Handbook of Phenomenological Psychopathology, https://oi.org/10.1093/oxfordhb/9780198803157.013.67.

Stanghellini, G., \& Rosfort, R. (2010). Affective temperament and personal identity. Journal of Affective Disorders, 126, 317-320.

Stanghellini, G., \& Rosfort, R. (2013a). Emotions and personhood. Exploring fragility - Making sense of vulnerability. Oxford: Oxford University Press.

Stanghellini, G., \& Rosfort, R. (2013b). Borderline depression. A desperate vitality. Journal of Consciousness, 20(7-8), 153-177.

Strawson, G. (2008). Against narrativity. In G. Strawson: Real Materialism and Other Essays (pp. 189-207). Oxford: Clarendon.

Strawson, G. (2010). Narrativity and non-narrativity. Wiley Interdisciplinary Reviews: Cognitive Science, 1(6), $775-780$.

Strawson, G. (2017). The subject of experience. Oxford: Oxford University Press.

Strawson, G. (2018). Things that bother me. Death, freedom, the self etc. New York: New York Review Books.

Strawson, G. (2020). Narrabable: On the use of the notion of narrative in ethics \& psychology. In E. Nahmias, T. W. Polger \& W. Zhao (Eds.): The Natural Method. Essays on Mind, Ethics, and Self in Honor of Owen Flanagan. Cambridge, MA: MIT press.

Velleman, J. D. (2006). The self as narrator. In J. D. Velleman: Self to Self: Selected Essays (pp. 203-223). Cambridge: Cambridge University press.

Wilkinson-Ryan, T., \& Westen, D. (2000). Identity disturbance in borderline personality disorder: An empirical investigation. American Journal of Psychiatry, 157(4), 528-541.

Wright, A. G. C., Hallquist, M. N., Beeney, J. E., \& Pilkonis, P. A. (2013). Borderline personality pathology and the stability of interpersonal problems. Journal of Abnormal Psychology, 122(4), 1094-1100.

Zahavi, D. (2007). Self and other. The limits of narrative understanding. In D. Hutto (Ed.), Narrative and understanding persons. Cambridge: Cambridge University Press.

Zahavi, D. (2010). Minimal self and narrative self: A distinction in need of refinement. In T. Fuchs, H. C. Sattel, a. P. Henningsen (Eds.): The Embodied Self: Dimensions, Coherence and Disorders. Stuttgart: Schattauer. 
Zandersen, M., \& Parnas, J. (2019). Identity disturbance, feelings of emptiness, and the boundaries of the schizophrenia spectrum. Schizophrenia Bulletin, 45(1), 106-113.

Publisher's note Springer Nature remains neutral with regard to jurisdictional claims in published maps and institutional affiliations.

\section{Affiliations}

\section{Philipp Schmidt ${ }^{1,2,3} \cdot$ Thomas Fuchs $^{3}$}

$\triangle$ Philipp Schmidt

schmidt@phil.tu-darmstadt.de; pschmidt.philosophy@gmail.com

1 Department of Philosophy, Technical University Darmstadt, Darmstadt, Germany

2 Department of Philosophy, University of Würzburg, Würzburg, Germany

3 Department of General Psychiatry, Center for Psychosocial Medicine, University of Heidelberg, Heidelberg, Germany 